\title{
Monitoring of water and carbon fluxes using a land data assimilation system: a case study for southwestern France
}

\author{
C. Albergel $^{1}$, J.-C. Calvet ${ }^{1}$, J.-F. Mahfouf ${ }^{1}$, C. Rüdiger ${ }^{1, *}$, A. L. Barbu ${ }^{1}$, S. Lafont ${ }^{1}$, J.-L. Roujean ${ }^{1}$, J. P. Walker ${ }^{2, *}$, \\ M. Crapeau ${ }^{3, * *}$, and J.-P. Wigneron ${ }^{3}$ \\ ${ }^{1}$ CNRM/GAME (Météo-France, CNRS), URA 1357, Toulouse, France \\ ${ }^{2}$ Department of Civil and Environmental Engineering, The University of Melbourne, Melbourne, Australia \\ ${ }^{3}$ Unité de recherche Ecologie fonctionnelle et Physique de l'Environnement (INRA), Villenave d'Ornon, France \\ *now at: Department of Civil Engineering, Monash University, Clayton, Australia \\ *** now at: EUMETSAT, Darmstadt, Germany
}

Received: 17 February 2010 - Published in Hydrol. Earth Syst. Sci. Discuss.: 3 March 2010

Revised: 14 June 2010 - Accepted: 15 June 2010 - Published: 29 June 2010

\begin{abstract}
A Land Data Assimilation System (LDAS) able to ingest surface soil moisture (SSM) and Leaf Area Index (LAI) observations is tested at local scale to increase prediction accuracy for water and carbon fluxes. The ISBAA-gs Land Surface Model (LSM) is used together with LAI and the soil water content observations of a grassland at the SMOSREX experimental site in southwestern France for a seven-year period (2001-2007). Three configurations corresponding to contrasted model errors are considered: (1) best case (BC) simulation with locally observed atmospheric variables and model parameters, and locally observed SSM and LAI used in the assimilation, (2) same as (1) but with the precipitation forcing set to zero, (3) real case (RC) simulation with atmospheric variables and model parameters derived from regional atmospheric analyses and from climatological soil and vegetation properties, respectively. In configuration (3) two SSM time series are considered: the observed SSM using Thetaprobes, and SSM derived from the LEWIS L-band radiometer located $15 \mathrm{~m}$ above the ground. Performance of the LDAS is examined in the three configurations described above with either one variable (either SSM or LAI) or two variables (both SSM and LAI) assimilated. The joint assimilation of SSM and LAI has a positive impact on the carbon, water, and heat fluxes. It represents a greater impact than assimilating one variable (either LAI or SSM). Moreover, the LDAS is able to counterbalance large errors in the precipitation forcing given as input to the model.
\end{abstract}

Correspondence to: J.-C. Calvet (jean-christophe.calvet@meteo.fr)

\section{Introduction}

Soil moisture is a key variable in short- and medium-range meteorological modelling as well as in climate and hydrological studies. Over vegetated areas, soil moisture can control plant transpiration. Continuous land surface processes such as the evolution of soil moisture, plant transpiration and soil evaporation can be modelled with Land Surface Models (LSM). Global Surface Soil Moisture (SSM) products are now operationally available from microwave spaceborne instruments such as ASCAT (Advanced Scatterometer onboard METOP, Wagner et al., 2007), the Advanced Microwave Scanning Radiometer for EOS (AMSR-E) sensor (Njoku et al., 2003, for the official product and Owe et al., 2001, 2008, for a new retrieval product), or will be available from the recently launched SMOS (Soil Moisture and Ocean Salinity, ESA/CNES, Kerr et al., 2001, 2007) satellite dedicated to the observation of the microwave brightness temperature (TB) at L-band, and from SMAP (Soil Moisture Active Passive, Entekhabi et al., 2004) which is scheduled for launch in 2015. While microwave remote sensing provides global maps of SSM (Schmugge, 1983), combining this information with LSM simulations through a Land Data Assimilation System (LDAS) allows the root zone soil moisture $\left(w_{2}\right)$ to be retrieved as demonstrated by several authors (Entekhabi et al., 1994; Houser et al., 1998; Walker et al., 2001; Ragab, 1995; Sabater et al., 2007). For that purpose, a LSM including a representation of a thin topsoil layer consistent with the remotely sensed parameter is required. The LSM representation of other biophysical variables observable from space is

Published by Copernicus Publications on behalf of the European Geosciences Union. 
an additional asset, as it permits to better assess and constrain the simulations.

SSM permits to improve the representation of $w_{2}$ which impacts the partitioning between latent and sensible heat (Shukla and Mintz, 1982). Similarly, the Leaf Area Index (LAI) is a key factor that impacts the exchanges of water vapour and $\mathrm{CO}_{2}$ between the vegetation canopy and the atmosphere. It is a vegetation physiological parameter of interest for the simulation of hydrological processes (Jarlan et al., 2008). The ISBA-Ags model, a $\mathrm{CO}_{2}$-responsive version of the ISBA LSM used at Météo-France (Calvet et al., 1998, 2004, 2008; Gibelin et al., 2006) is able to simulate photosynthesis and plant growth. The simulated vegetation biomass and LAI evolve dynamically in response to meteorological forcing conditions. As for SSM, the impact of assimilating LAI in a LDAS has also been investigated (Jarlan et al., 2008).

In a previous study, Sabater et al. (2008) presented a joint assimilation of SSM and LAI in ISBA-A-gs at the SMOSREX experimental site, in southwestern France (De Rosnay et al., 2006) over the 2001-2004 period. They used a simplified 2-D-Var assimilation system with a 10-day assimilation window. They underlined the positive impact of assimilating SSM and LAI on $w_{2}$, LAI and biomass model simulations. Moreover, they showed that the assimilation is able to compensate for large errors in the precipitation observations on the forcing used as input to the model.

Following Sabater et al. (2008), the present study focuses on the assimilation of SSM and LAI into ISBA-A-gs, at the SMOSREX experimental site. Further steps are made by:

- using a simplified version of an Extended Kalman Filter (EKF, Mahfouf et al., 2009; Draper et al., 2009) here noted SEKF, with a short assimilation interval of $24 \mathrm{~h}$ fully compatible with atmospheric assimilation systems used in numerical weather prediction systems,

- considering a longer period of seven years (20012007) at the SMOSREX experimental site, including all ranges of climatic conditions,

- imposing contrasted model errors through different model configurations using observed or synthetic atmospheric variables, locally observed or climatological soil and vegetation properties.

- assimilating, along with direct observations of SSM, SSM estimates derived from L-band microwave TB measurements performed at SMOSREX with LEWIS (L-band radiometer for Estimating Water in Soils),

- using, along with direct observations of LAI, LAI estimates derived from VIS and SWIR reflectance measurements performed at SMOSREX with a reflectancemeter,

- assessing the impact of the assimilation in terms of surface and root zone soil moisture, LAI but also energy (sensible and latent heat) and $\mathrm{CO}_{2}$ fluxes as the latter were observed at SMOSREX in 2005, 2006 and 2007,

- analysing the impact on the surface fluxes of assimilating SSM and LAI, either separately or jointly.

Real case simulations (Sect. 2.1) use atmospheric forcing data from the SAFRAN analysis (Quintana-Seguí et al., 2008; Habets et al., 2008) over France and either in situ soil moisture observations or L-band TB derived soil moisture estimates are considered. As in Sabater et al. (2008), the robustness of the LDAS is tested using no precipitation conditions throughout the seven year period, i.e. $w_{2}$ simulations relying on the assimilation of surface soil moisture, only. An accurate model of land surface processes is required for NWP modelling and the use of a LDAS is an adequate manner to correct soil moisture when observations are available. For other applications (e.g. hydrology or drought monitoring), root-zone soil moisture estimates can be obtained by applying an exponential filter to the SSM time series. Hence, along with the $w_{2}$ analysed by the SEKF in unknown precipitation conditions (i.e. relying on the SSM analysis to retrieve $w_{2}$, only), a simple recursive formulation of an exponential filter (Wagner et al., 1999; Albergel et al., 2008) is evaluated, where SSM alone is used to retrieve $w_{2}$ variability.

\section{Material and methods}

\subsection{Land surface model: ISBA-A-gs}

The ISBA (Interaction between Soil Biosphere and Atmosphere) LSM, developed by Noilhan and Planton (1989) and further improved by Noilhan and Mahfouf (1996), aims at describing the surface processes in weather and climate models. It was implemented into numerical weather forecast models, hydrological models and global climate models. ISBA describes the evolution of land surface state variables (surface temperature, soil temperature, surface soil moisture, root-zone soil moisture and canopy interception reservoir), together with the surface energy fluxes (sensible, latent and ground heat fluxes). ISBA-A-gs is a further development of ISBA able to account for the atmospheric $\mathrm{CO}_{2}$ concentration on stomatal aperture (Calvet et al., 1998, 2004, 2008; Gibelin et al., 2006). Also, photosynthesis and its coupling with stomatal conductance at a leaf level are accounted for. The vegetation net assimilation of $\mathrm{CO}_{2}$ is estimated and used as an input to a simple vegetation growth sub-model able to predict LAI. ISBA-A-gs is able to simulate Gross Primary Production (GPP), Net Ecosystem Exchange (NEE), and LAI, fully consistent with the modelled sensible and latent heat fluxes, and with soil moisture. ISBA-A-gs has recently been implemented in the pre-operational modelling platform of Météo-France, SURFEX (Martin et al., 2007; Le Moigne et al., 2009). In this study, SURFEX is used "offline" from the atmospheric model. Three control simulations (also referred 
Table 1. Main soil and vegetation parameters used for the SMOSREX grassland in the ISBA-A-gs model, for the best case (i.e. specific atmospheric forcing, soil and vegetation parameters of SMOSREX) and real case simulations (i.e. atmospheric forcing from the SAFRAN analysis, soil and vegetation parameters from SAFRAN and ECOCLIMAP data base).

\begin{tabular}{|c|c|c|c|c|}
\hline Parameter & Symbol & Unit & Best case value & Real case value \\
\hline \multicolumn{5}{|c|}{ Soil Parameters } \\
\hline Soil depth & $d_{2}$ & $\mathrm{~m}$ & 0.95 & 1.82 \\
\hline Sand content & SAND & $\%$ & 32.0 & 33.25 \\
\hline Clay content & CLAY & $\%$ & 22.8 & 29.25 \\
\hline Field capacity & $w_{\mathrm{fc}}$ & $\mathrm{m}^{3} \mathrm{~m}^{-3}$ & 0.30 (set to) & 0.29 (calculated) \\
\hline Wilting point & $w_{\text {wilt }}$ & $\mathrm{m}^{3} \mathrm{~m}^{-3}$ & 0.17 (set to) & 0.20 (calculated) \\
\hline \multicolumn{5}{|c|}{ Vegetation parameters } \\
\hline Mesophyll conductance in well-watered condition & $g_{\mathrm{m}} *$ & $\mathrm{~mm} \mathrm{~s}^{-1}$ & 0.56 & 1 \\
\hline Critical extractable soil moisture content & $\theta_{c}$ & Dimensionless & 0.5 & 0.3 \\
\hline Soil moisture stress response strategy & - & - & Drought-tolerant & Drought-tolerant \\
\hline Maximum leaf span time & $\tau_{\mathrm{M}}$ & Days & 80 & 150 \\
\hline Minimum leaf area index & $\mathrm{LAI}_{\min }$ & $\mathrm{m}^{2} \mathrm{~m}^{-2}$ & 0.3 & 0.3 \\
\hline Cuticular conductance & $g_{\mathrm{c}}$ & $\mathrm{mm} \mathrm{s}^{-1}$ & 0.3 & 0.25 \\
\hline $\begin{array}{l}\text { SLA (specific leaf area) sensitivity to } N_{L} \text { (leaf nitrogen } \\
\text { concentration) }\end{array}$ & $e$ & $\mathrm{~m}^{2} \mathrm{~kg}^{-1} \%^{-1}$ & 5.84 & 5.56 \\
\hline SLA at $N_{L}=0$ & $f$ & $\mathrm{~m}^{2} \mathrm{~kg}^{-1}$ & 6.32 & 6.73 \\
\hline Leaf nitrogen concentration & $N_{L}$ & $\%$ of dry mass & 1.4 & 1.3 \\
\hline
\end{tabular}

to as open-loop simulations) with ISBA-A-gs are used: (i) a "best case" (BC) simulation, using locally observed atmospheric variables with specific soil and vegetation parameters at the considered SMOSREX site; (ii) same as (i) but with the precipitation forcing set to zero; and (iii) a "real case" (RC) simulation, forced with atmospheric variables from the SAFRAN atmospheric analysis with soil and vegetation parameters from the ECOCLIMAP global data base of soils and ecosystems (Masson et al., 2003). In this study, the model only considers one grid point located at the SMOSREX experimental site. This is a first stage before developing the LDAS at larger scales within the SURFEX modelling platform. Open-loop simulations correspond to LDAS simulations with no SSM and LAI values used in the LDAS.

SAFRAN (Système d'analyse fournissant des renseignements atmosphériques à la neige) is a mesoscale analysis system for surface atmospheric variables (Durand et al., 1993). The SAFRAN analysis provides key atmospheric forcing variables (precipitation, air temperature, air humidity, wind speed, incident radiation) using information from more than 1000 meteorological stations and more than 3500 daily rain gauges throughout France. An optimal interpolation method is used to spatially interpolate the observations. It was shown that a good correlation exists between the SAFRAN data base and independent in situ observations (Quintana-Seguí et al., 2008).

The values of the main soil and vegetation parameters used in the ISBA-A-gs simulations over the SMOSREX grassland site are presented in Table 1 . They are derived from the simulation of Calvet (2000) for the MUREX test site, observations at SMOSREX, and from Gibelin et al. (2006). Differences exist between RC and BC parameters. For example, field capacity and wilting point are fixed to 0.30 and $0.17 \mathrm{~m}^{3} \mathrm{~m}^{-3}$, respectively, for $\mathrm{BC}$, whereas for $\mathrm{RC}$, they are derived from the clay content observations using the relationships given by Noilhan and Mahfouf (1996): 0.29 and $0.20 \mathrm{~m}^{3} \mathrm{~m}^{-3}$, respectively. One of the main differences between the two sets of parameters is soil depth, $0.95 \mathrm{~m}$ for BC and $1.82 \mathrm{~m}$ (provided by ECOCLIMAP) for RC. However, to obtain comparable volumetric soil moisture values between the two simulations, soil depth was set to the unique value of $0.95 \mathrm{~m}$.

\subsection{Extended Kalman Filter}

The key update equation of the Extended Kalman Filter is:

$x_{\mathrm{a}}^{t}=x_{\mathrm{f}}^{t}+\mathbf{B H}^{\mathrm{T}}\left(\mathbf{H B H} \mathbf{H}^{\mathrm{T}}+\mathbf{R}\right)^{-1}\left(\boldsymbol{y}_{\mathrm{o}}^{t}-h\left(\boldsymbol{x}_{\mathrm{f}}^{0}\right)\right)$

where $\boldsymbol{x}$ is a control vector of dimension two ( $\left.w_{2}, \mathrm{LAI}\right)$ propagated by the ISBA-A-gs model, and $\boldsymbol{y}_{\mathrm{O}}$ the observation vector of dimension two (SSM, LAI), also. The observation operator $h$, is the model counterpart of the observations:

$\boldsymbol{y}^{t}=h\left(\boldsymbol{x}^{0}\right)$

The "a", "f" and "o" subscripts denote analysis, forecast and observation, respectively. $\mathbf{B}$ is the background error covariance matrix and $\mathbf{R}$ the observation error covariance matrix. 
Since $h$ can be non-linear, the Jacobian of $h, \mathbf{H}$ (and its transpose $\mathbf{H}^{\mathrm{T}}$ ) appears in Eq. (1). $\mathbf{H}$ is defined as:

$\mathbf{H}_{i j}=\frac{\partial y_{i}^{t}}{\partial x_{j}^{0}}$

which gives the following Jacobian matrix:

$\mathbf{H}=\left(\begin{array}{cc}\frac{\partial \mathrm{SSM}^{t}}{\partial w_{2}^{0}} & \frac{\partial \mathrm{SSM}^{t}}{\partial \mathrm{LAI}^{0}} \\ \frac{\partial \mathrm{LAI}^{t}}{\partial w_{2}^{0}} & \frac{\partial \mathrm{LAI}^{t}}{\partial L A I^{0}}\end{array}\right)$

The $t$ and 0 superscripts stand for time $(t)$ and for the initial time $(t=0)$. The initial state at the beginning of an assimilation window is analysed via the information provided by an observation at the end of the assimilation window (Rüdiger et al., 2010). In this approach, the increments are applied at the end of a 1-day assimilation interval which is the main difference from the "simplified 2-D-Var (2-dimensional variational data assimilation scheme)" proposed by Balsamo et al. (2004). The elements of the Jacobian matrix are estimated by finite differences, by individually perturbing each component $x_{j}$ of the control vector $\boldsymbol{x}$ by a small amount $\delta x_{j}$ to get for each integration a column of the matrix $\mathbf{H}$ :

$\mathbf{H}_{i j}=\frac{y_{i}\left(\boldsymbol{x}+\delta x_{j}\right)-y_{i}(\boldsymbol{x})}{\delta x_{j}}$

The background error covariance matrix $\mathbf{B}$ is assumed to be constant at the start of each analysis cycle. Observations are assimilated over a $24 \mathrm{~h}$ interval at 06:00 UTC, this time was set to mimic the acquisition time of the SMOS satellite. As the control vector is the liquid part of SSM, to avoid frozen soil effect, SSM estimates to be assimilated are removed below a simulated surface temperature threshold of $4{ }^{\circ} \mathrm{C}$.

\subsection{Recursive exponential filter}

In previous studies, Albergel et al. $(2008,2009)$ assessed the retrieval of $w_{2}$ via a recursive formulation of an exponential filter of the form $\exp (-t / T)$ relying solely on SSM estimates, to retrieve $w_{2}$ variability. The $T$ parameter is a characteristic time length, a surrogate parameter taking into account the different processes that affect the temporal dynamics of water content in the soil. The considered formulation is presented in Eqs. (6) to (8). It is a recursive formulation of the exponential filter of Wagner et al. (1999). The result is a Soil Water Index (SWI) ranging from 0 to 1.

$\mathrm{SWI}_{(n)}=\mathrm{SWI}_{(n-1)}+K_{n}\left(\mathrm{~ms}\left(t_{n}\right)-\mathrm{SWI}_{(n-1)}\right)$

where $\mathrm{ms}$ is the SSM value normalised between 0 and 1 using the min and max values of the considered time series. The gain $K$ at time $t_{n}$ is given by:

$$
K_{n}=\frac{1}{1+\sum_{i}^{n-1} e^{-\frac{\left(t_{n}-t_{i}\right)}{T}}}
$$

This gain may also be written in its recursive form as:

$K_{n}=\frac{K_{n-1}}{K_{n-1}+e^{-\frac{\left(t_{n}-t_{n-1}\right)}{T}}}$

The range of the gain $K$ is $[0,1]$. In the presence of extensive temporal data gaps (relative to the filter time scale), $K$ tends toward unity. In that particular case, the previous estimates are disregarded when new observations are obtained and the new estimates take on the value of the new observations. For the initialisation of the filter, $K_{1}=1$ and $\mathrm{SWI}_{(1)}=\mathrm{ms}\left(t_{1}\right)$. The exponential filter does not require any atmospheric forcing data set and relies on SSM time series, only.

The value of $T$ used in this study is equal to 11 days. It corresponds to the value found in Albergel et al. (2008) for the SMOSREX site, that minimised the difference between the calculated SWI, using in situ SSM $(0-6 \mathrm{~cm})$, and the SWI derived from the observed soil moisture profile at the SMOSREX site (see below).

\subsection{The SMOSREX experimental site and data set}

Located at the ONERA (Office National d'Etudes et de Recherches Aérospatiales) site of Fauga-Mauzac, near Toulouse, in southwestern France, the SMOSREX long-term experiment (De Rosnay et al., 2006) aims at improving the modelling of the microwave L-band emission of the soilvegetation system as well as improving the understanding of soil-plant-atmosphere interactions. A grassland field is equipped with an environment monitoring instrumentation including a weather station with soil moisture profiles, a flux station, and downward looking remote sensing instruments at $15 \mathrm{~m}$ above the ground. Surface shortwave reflectances are determined thanks to two CIMEL radiancemeters. Bipolarized L-band brightness temperatures are measured by the LEWIS radiometer. The LEWIS accuracy is $0.2 \mathrm{~K}$ and its beamwidth is $13.5^{\circ}$ at $-3 \mathrm{~dB}$. A full technical description of LEWIS can be found in Lemaitre et al. (2004). Net radiation $(\mathrm{Rn})$ has been measured at SMOSREX since 2001 at half hourly time steps. Sensible heat (H), latent heat (LE), and $\mathrm{CO}_{2}$ fluxes have been measured since 2005. The flux measurements are performed through the eddy covariance micrometeorological method (Moncrieff et al., 1997; Aubinet et al., 2000) and data have been available since 2005. The $\mathrm{CO}_{2}, \mathrm{H}$ and LE fluxes observed at SMOSREX were found to correlate well with the ISBA-A-gs simulations (Albergel et al., 2010).

At SMOSREX, all the atmospheric forcing variables required to run ISBA-A-gs are measured, i.e. half-hourly observations of atmospheric pressure, air relative humidity, air temperature, long wave and short wave incident radiation, rain rate and wind speed. Also, hourly estimates of the same atmospheric variables are available from the SAFRAN mesoscale atmospheric analysis system (Durand et al., 1993; Quintana-Seguí et al., 2008). SAFRAN covers France at a spatial resolution of $8 \mathrm{~km}$. 

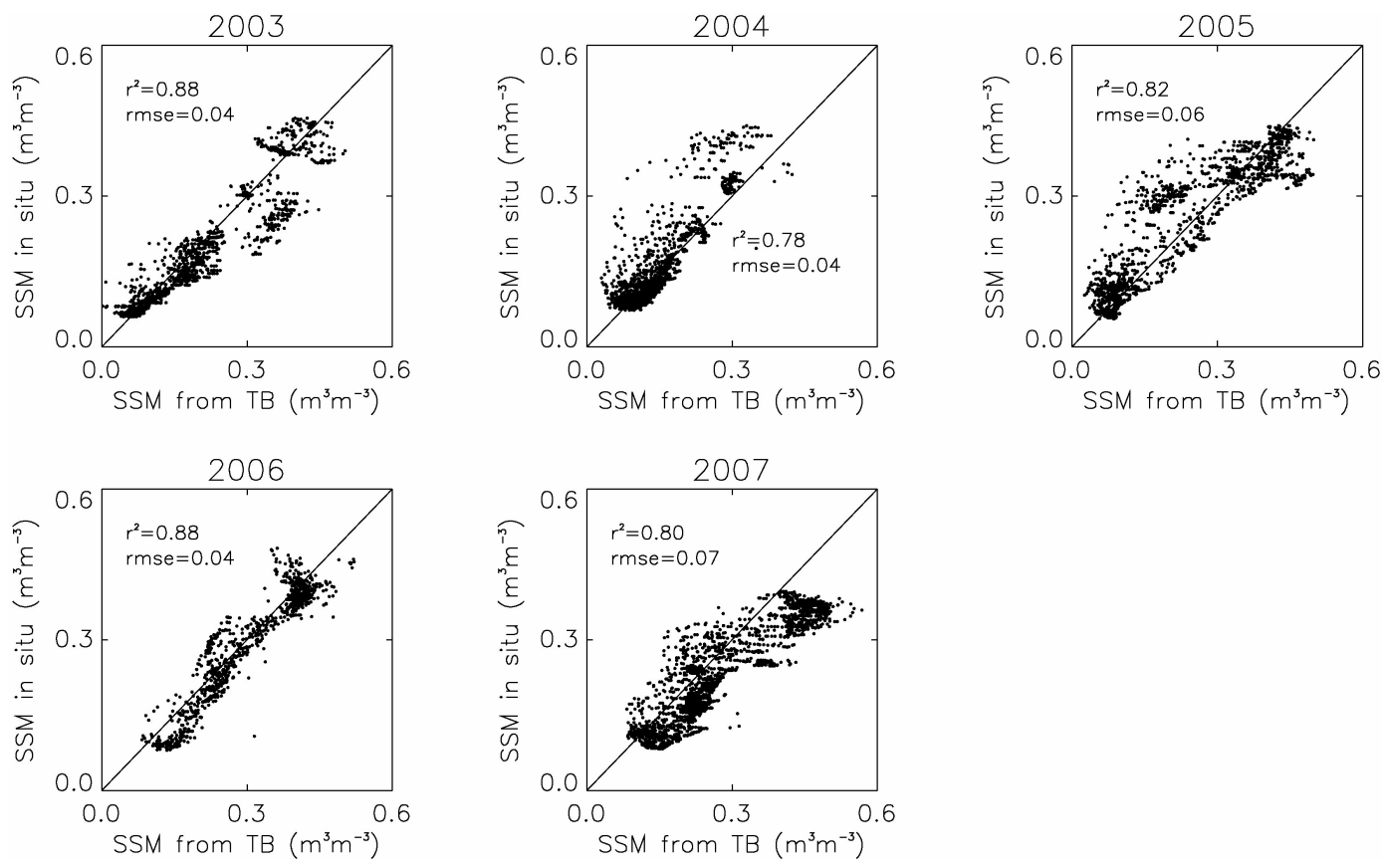

Fig. 1. Observed vs. retrieved SSM from brightness temperature measurements at SMOSREX for each year of the 2003-2007 period. RMSE values are expressed in units of $\mathrm{m}^{3} \mathrm{~m}^{-3}$.

\subsubsection{Soil moisture}

Soil moisture was measured by ThetaProbes (Delta-T Devices) at ten depths, 0-6 (inserted vertically), 10, 20, 30, 40, $50,60,70,80,90 \mathrm{~cm}$ (inserted horizontally at their respective depth) with an half hourly time step since January 2001. From those measurements it is possible to estimate the rootzone soil moisture content $w_{2}\left(\mathrm{~m}^{3} \mathrm{~m}^{-3}\right)$, integrated over the root-zone profile $(0-95 \mathrm{~cm})$. A depth of $0.95 \mathrm{~m}$ is used for both RC and BC simulations, in order to use the soil moisture observations for verification. The root biomass was not measured at SMOSREX. Over the grassland of the MUREX site, located in the same region as SMOSREX, most roots were found in the $0.25 \mathrm{~m}$ surface soil layer and few roots were observed in deeper layers, down to $0.70 \mathrm{~m}$ (Calvet et al., 1999). It must be noted that, in this study, a simple force-restore version of the model hydrology is used. In fact, $w_{2}$ represents the volumetric soil moisture of a single soil layer ( 0 $0.95 \mathrm{~m}$ ) including the root-zone and deeper layers contributing to the evapotranspiration flux through capillarity rises. As at SMOSREX, soil moisture is observed from the surface $(0-6 \mathrm{~cm})$ and each $0.1 \mathrm{~m}$ until almost one meter, using a $d_{2}$ value of $0.95 \mathrm{~m}$ in the ISBA-A-gs model permits to compare the modelled $w_{2}$ with the observed $w_{2}$ values.

Three profiles were used to determine the root zone soil moisture. At the surface, four probes were vertically installed at four different locations of the study area and the average value of these observations used as an estimate of SSM. In this study, the SSM values used in the assimilation are the average surface soil moisture $(0-6 \mathrm{~cm})$ observed from Jan- uary 2001 to December 2007 from those four probes. Halfhourly SSM observations are available. However, in order to mimic the frequency of satellite derived SSM only one SSM observation is assimilated every 3 days at 06:00 UTC. For the first year (2001) of SMOSREX, Sabater et al. (2007), found average daily standard deviation of SSM and $w_{2}$ of $\sigma$ $(\mathrm{SSM})=0.03 \mathrm{~m}^{3} \mathrm{~m}^{-3}$ and $\sigma\left(w_{2}\right)=0.02 \mathrm{~m}^{3} \mathrm{~m}^{-3}$, respectively.

The SSM resulting from the inversion of the L-band TB measured by LEWIS is available from 2003 to 2007. Over this period, the RMSE (root mean square error) between this data set and the in situ SSM is about $0.06 \mathrm{~m}^{3} \mathrm{~m}^{-3}$. The LEWIS TB is used to retrieve SSM by inverting the L-band microwave emission model of the biosphere (LMEB) radiative transfer model (Wigneron et al., 2007), using a method based on Saleh et al. (2007). Figure 1 presents, for each year of the 2003-2007 period, a comparison between the in situ SSM and the TB-derived SSM. There is no clear explanation for the year to year score of the TB-derived SSM. However, it can be noted that the highest $r^{2}$ scores are found for 2003 , 2005 and 2006, which were marked by significant summer droughts in southwestern France, as opposed to 2004 and 2007. This could be caused by the litter effect on the L-band TB measured at SMOSREX, described in Saleh et al. (2007). Indeed, the dead vegetation material tends to intercept and accumulate rainwater, thus attenuating the soil emission. It is likely that this effect is more pronounced during wet years (more intercepted water and more vegetation material due to enhanced net primary production, as shown by Albergel et al., 2010). 


\subsubsection{LAI from surface reflectance measurements}

The incoming (downward) solar radiation at several wavelengths and the (upward) luminance reflected by the grassland at a $40^{\circ}$ incidence angle, are measured over the grassland using two CIMEL radiancemeters, from July 2003 to December 2007. From those measurements, it is possible to determine the surface reflectance at five wave-lengths, from the visible to the short-wave infrared (blue: $430-470 \mathrm{~nm}$, green: $506.5-591.5 \mathrm{~nm}$, red: $621.5-674.5 \mathrm{~nm}$, near infrared: $792-883 \mathrm{~nm}$ and short-wave infrared: $1557.7-1722.5 \mathrm{~nm}$ ). A method developed by Roujean and Lacaze (2002) permits to produce LAI estimates, from the surface reflectances. Also, manual destructive measurements of the vegetation characteristics such as height, biomass, dry mater, water content and LAI were frequently performed at SMOSREX from 2001 to 2006. In a previous study using a 2-D-Var assimilation method with ISBA-A-gs over SMOSREX, Sabater et al. (2008), used a spline function to interpolate the observed LAI over the 2001-2004 period in order to assimilate an observation every 10 days. Because surface reflectance is available from July 2003, the same LAI as the one described in Sabater et al. (2008) is used from January 2001 to July 2003. In this study, one LAI observation every 10 days is used, which is close to availability of satellite derived LAI products.

\subsection{Setting observational and background errors}

The description of the error matrices is a key aspect of data assimilation. Their accurate specification is a major issue in the implementation of a LDAS (Crow and Reichle, 2008; Reichle et al., 2008). The correction of the system state depends on the background and observation errors prescription. The observational error for SSM, $\mathbf{R}_{\mathrm{SSM}}$, was set to $0.06^{2}$ $\left(\mathrm{m}^{3} \mathrm{~m}^{-3}\right)^{2}$ and the background error for $w_{2}, \mathbf{B}_{w 2}$ set to $0.02^{2}$ $\left(\mathrm{m}^{3} \mathrm{~m}^{-3}\right)^{2}$, following the finding of Sabater et al. (2008). Despite of the $0.03 \mathrm{~m}^{3} \mathrm{~m}^{-3}$ standard deviation value derived from SSM automatic measurements, they found that doubling this value was more appropriate. This is consistent with the estimated error found for the ASCAT remotely sensed SSM (Albergel et al., 2009). In both Sabater et al. (2008) and Jarlan et al. (2008), the observational LAI error was fixed at a value of $1 \mathrm{~m}^{2} \mathrm{~m}^{-2}$. As this value was found by Jarlan et al. (2008) to be too high during periods with low vegetation (from the end of summer to spring), they used a LAI background error (LAI) varying seasonally with LAI, by setting $\mathbf{B}_{\mathrm{LAI}}$ to $20 \%$ of the modelled LAI. In this study, it was decided to use this relative error of $20 \%$ for both $\mathbf{R}_{\mathrm{LAI}}$ and $\mathbf{B}_{\mathrm{LAI}}$, as suggested by Rüdiger et al. (2010). Whereas $\mathbf{R}_{\mathrm{LAI}}$ and $\mathbf{B}_{\mathrm{LAI}}$ are fixed for the three configurations considered in this study ( $\mathrm{BC}, \mathrm{BC}+0$ precipitation, $\mathrm{RC})$, different values are taken for $\mathbf{R}_{\mathrm{SSM}}$ and $\mathbf{B}_{w 2}$. In order to illustrate the impact of the error statistics on the performance of the LDAS, a $\mathrm{BC}+0$ precipitation configuration is evaluated. A higher background error on $w_{2}$, more consistent with the degraded performance of the model in the $\mathrm{BC}+0$ precipitation configuration, is prescribed $\left(\mathbf{B}_{w 2}=0.06^{2}\left(\mathrm{~m}^{3} \mathrm{~m}^{-3}\right)^{2}\right)$. Prescribing high background errors gives more weight to the SSM observations and will allow the LDAS to retrieve the main seasonal characteristics of $w_{2}$. In the same way, when considering the RC simulation, it can be assumed that the model error is higher than for BC. Hence, after running the LDAS with assimilation of both LAI and SSM for several values of $\mathbf{B}_{w 2}$ (not shown), it was found that $\mathbf{B}_{w 2}=0.022^{2}\left(\mathrm{~m}^{3} \mathrm{~m}^{-3}\right)^{2}$ optimised the LDAS performance. Finally, the assimilation of TB-derived SSM in the RC simulation (instead of in situ observations) has to consider a higher $\mathbf{R}_{\mathrm{SSM}}$ value, as TBderived SSM is less accurate than in situ observations. A value of $\mathbf{R}_{\mathrm{SSM}}=0.062^{2}\left(\mathrm{~m}^{3} \mathrm{~m}^{-3}\right)^{2}$ is obtained. Table 2 summarizes all the different error statistics used in this study.

\subsection{Computing statistical scores}

The impact of assimilating LAI and SSM is examined for each individual year and for the whole period by comparing observed variables $\left(w_{2}, \mathrm{LAI}\right.$, the $\mathrm{CO}_{2}$ flux, $\mathrm{LE}$ and $\left.\mathrm{H}\right)$ to the open loop simulation, and to the analysis. A number of scores are computed: the squared correlation coefficient $\left(r^{2}\right)$, the mean bias, and the RMSE. When considering LAI, SSM and $w_{2}$ time series, the Nash-Sutcliffe criterion $(N)$ is also computed:

$$
N=1-\frac{\sum_{i}\left(\operatorname{obs}(i)-x_{a}(i)\right)^{2}}{\sum_{i}\left(x_{\mathrm{a}}(i)-\overline{x_{\mathrm{a}}(i)}\right)^{2}}
$$

where $N$ can range from $-\infty$ to 1 . A value of 1 corresponds to a perfect match between modelled and observed data. A value of 0 indicates that the model predictions are as accurate as using the mean of the observed data, whereas negative values occur if the observed mean is a better predictor than the model output (Nash and Sutcliffe, 1970).

\section{Results}

\subsection{Open loop simulations and SSM data processing}

Figure 2 presents the open-loop simulation of $w_{2}$ for both $\mathrm{BC}$ and $\mathrm{RC}$ along with the observations. The LDAS used in this study is not coupled with the atmosphere and no air temperature and air humidity observations are assimilated. In Fig. 2, the LDAS is used in a configuration where no SSM or LAI values are used in the assimilation. The $\mathrm{BC} w_{2}$ values are closer to the observations (statistical scores are presented in Table 3). The differences between BC and RC simulations are due to different soil and vegetation characteristics (Table 1) and to differences in the atmospheric forcing. In particular, while field capacity and wilting point values are derived 


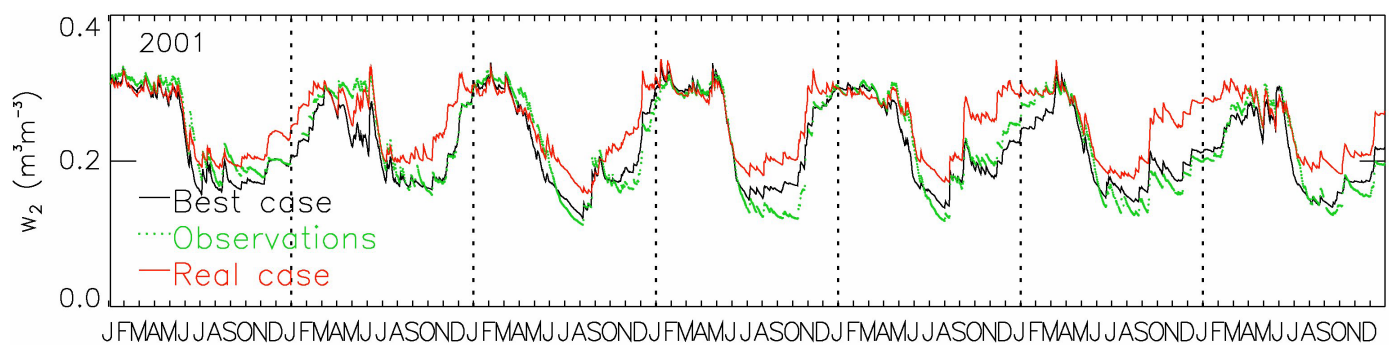

Fig. 2. Observed (green dots) vs. simulated $w_{2}$ using the ISBA-A-gs model in two configurations: (i) Best case, i.e. specific atmospheric forcing, soil and vegetation parameters of SMOSREX (black line) and (ii) Real case i.e. atmospheric forcing from the SAFRAN analysis with soil and vegetation parameters from SAFRAN and ECOCLIMAP data base (red line).
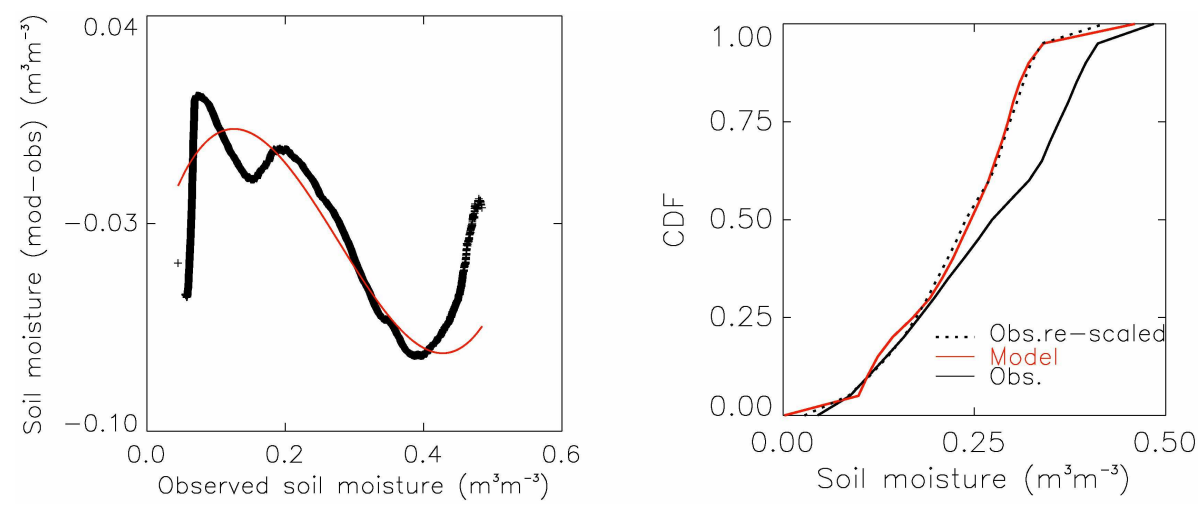

Fig. 3. Rescaling of the observed surface soil moisture data set to the real-case (RC) model simulations by matching its Cumulative Distribution Function (CDF) to the simulations of ISBA-A-gs. A polynomial fit (of third order) is used to remove the systematic differences between the two data set (red curve in left graph).

from observations in $\mathrm{BC}$, they are derived from the ECOCLIMAP look-up table in RC. Despite the different annual amplitude of the $\mathrm{BC}$ and $\mathrm{RC} w_{2}$ simulations, the impact of the weather variability on $w_{2}$ is reproduced reasonably well in the RC simulation based on SAFRAN.

In the context of the assimilation of soil moisture data, the considered observations need to be re-scaled to be consistent with the model climatology (Reichle and Koster, 2004; Drusch et al., 2005). Each soil moisture data set is characterized by its specific mean value, variability and dynamical range. ISBA-A-gs has its own soil moisture climatology with a specific dynamical range controlled by the values at wilting point and field capacity. Following Reichle and Koster (2004) and Drusch et al. (2005), the observed SSM was re-scaled by matching its Cumulative Distribution Function $(\mathrm{CDF})$ to the modelled surface soil moisture of ISBAA-gs so that the systematic differences are removed. The CDF matching was performed for $\mathrm{BC}$ and for RC simulations. From a technical point of view, the two SSM data sets (observed and modelled) are ranked and the differences between the corresponding elements of the two ranked data sets are computed (Draper et al., 2009). Then a polynomial fit (of third order) is used to remove the systematic differences between the two data sets. Figure 3 illustrates this methodology: Fig. 3 (left) presents the differences between the modelled (Best Case, configuration 1) and the observed SSM as a function of the observed SSM and a polynomial curve is used to re-scale the data set; Fig. 3 (right) presents the CDF of modelled (Best Case, configuration 1), observed and rescaled SSM data sets. Note that a specific CDF matching was performed for the best case and for the real case considering either observed SSM and TB-derived SSM. The implementation of the CDF matching technique is a critical issue. The use of a training period to calibrate the CDF polynomial was tested (using the first year, 2001, only). However, 2001 was not representative of the longer time series (2001-2007) and the resulting CDF matching failed to remove the systematic differences between observations and simulations. The whole 2001-2007 period was considered to perform the matching. Most of previous studies using this technique have applied it in a similar way. Indeed, in satellite applications, data may be scarce for the first months/years and it may be impossible to use independent data.

\subsection{Best case LDAS}

First the impact of assimilating LAI or SSM, either separately or jointly, was assessed. Table 3 presents the statistical 
Table 2. Observational and model error values ( $\mathbf{R}$ and $\mathbf{B}$, respectively) for the different experiments considered in this study. The values $\mathbf{R}_{\mathrm{LAI}}$ and $\mathbf{B}_{\mathrm{LAI}}$ are relative (\%) to the actual observation or model value of LAI.

\begin{tabular}{lccc}
\hline Configuration & $\mathbf{R}_{\mathrm{SSM}}\left(\mathrm{m}^{3} \mathrm{~m}^{-3}\right)^{2}$ & $\mathbf{B} w_{2}\left(\mathrm{~m}^{3} \mathrm{~m}^{-3}\right)^{2}$ & $\mathbf{R}_{\text {LAI }}$ and $\mathbf{B}_{\text {LAI }}(\%)$ \\
\hline BC & $0.060^{2}$ & $0.020^{2}$ & 20 \\
BC, no precipitation & $0.060^{2}$ & $0.060^{2}$ & 20 \\
RC & $0.060^{2}$ & $0.022^{2}$ & 20 \\
RC+assimilation of TB-derived SSM & $0.062^{2}$ & $0.022^{2}$ & 20 \\
\hline
\end{tabular}
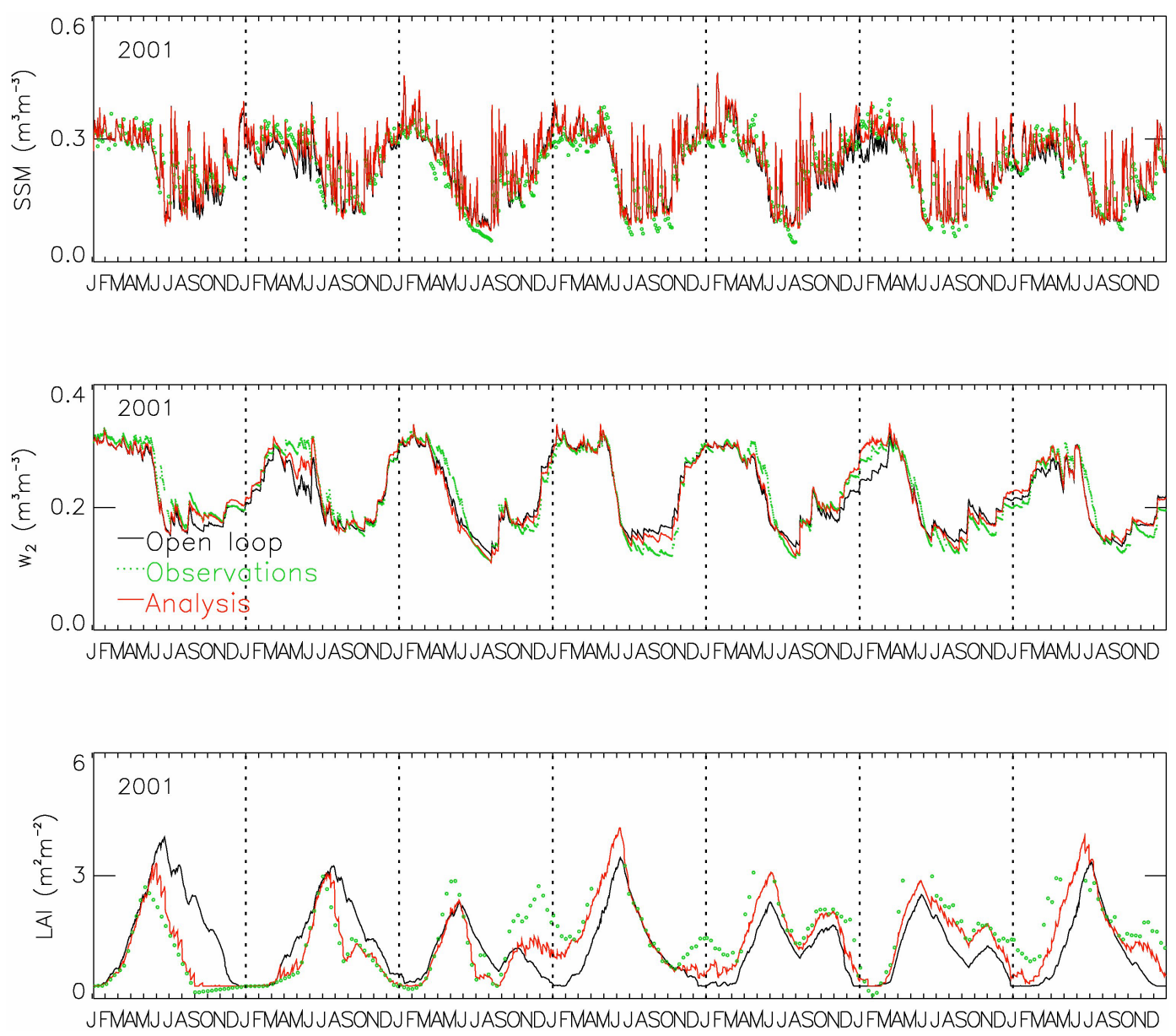

Fig. 4. Data assimilation system (LDAS) vs. open-loop best case (BC) simulations and observations over the SMOSREX experimental site for a seven year period (2001-2007). From top to bottom, SSM, $w_{2}$ and LAI with Black curve for the BC (i.e. specific atmospheric forcing, soil and vegetation parameters of SMOSREX), red line for the analysis (results of the assimilation) and the green dots for the observations.

scores for the different BC simulations: the reference openloop simulation, and the simulations constrained by LAI only, SSM only, and LAI jointly with SSM. For each simulation, scores on SSM, $w_{2}$, LAI, and on the $\mathrm{CO}_{2}$ flux, $\mathrm{H}$ and LE are presented for the whole considered period (20012007 for SSM, $w_{2}$, LAI and 2005-2007 for the $\mathrm{CO}_{2}$ flux, $\mathrm{H}$ and LE as these observations are available only from 2005 onwards). Table 3 shows that the open-loop ISBA-A-gs BC simulation, already presents skilful statistical scores for most variables, apart from LAI (negative value of $N$ ). The assimilation of SSM and LAI observations permits to increase these scores.

Assimilating LAI only (one observation every ten days) has a small impact on SSM, $w_{2}$ and energy fluxes. However, it has an impact on the LAI itself, increasing $r^{2}$ from 0.21 to 0.80 and $N$ from -0.22 to 0.74 , also reducing the 
Table 3. Model and LDAS scores (squared correlation coefficient, mean bias, root mean square error (RMSE) and Nash-Sutcliffe criterion $N$ ) on state variables (SSM, $w_{2}$ and LAI) and surface fluxes $\left(\mathrm{CO}_{2}\right.$ flux, $\mathrm{H}$ and LE) for the SMOSREX grassland, in "best case" and "real case" configurations. Note that $N$ is not calculated for the $\mathrm{CO}_{2}$ flux, $\mathrm{H}$ and LE.

\begin{tabular}{|c|c|c|c|c|c|}
\hline & & $r^{2}$ & bias & RMSE & $N$ \\
\hline \multicolumn{6}{|l|}{ Best case } \\
\hline \multirow{6}{*}{ Open-loop } & SSM & 0.69 & 0.03 & 0.06 & 0.61 \\
\hline & $w_{2}$ & 0.91 & 0.004 & 0.02 & 0.90 \\
\hline & LAI & 0.21 & 0.18 & 0.88 & -0.22 \\
\hline & $\mathrm{CO}_{2}$ & 0.59 & -2.15 & 3.80 & l \\
\hline & $\mathrm{H}$ & 0.79 & -8.95 & 44.15 & I \\
\hline & LE & 0.64 & -2.50 & 42.35 & / \\
\hline \multirow{6}{*}{ Assimilation LAI only } & SSM & 0.69 & 0.03 & 0.07 & 0.60 \\
\hline & $w_{2}$ & 0.91 & 0.005 & 0.02 & 0.90 \\
\hline & LAI & 0.80 & 0.20 & 0.41 & 0.74 \\
\hline & $\mathrm{CO}_{2}$ & 0.62 & -1.84 & 3.53 & I \\
\hline & $\mathrm{H}^{2}$ & 0.77 & -8.46 & 44.50 & / \\
\hline & LE & 0.62 & 0.37 & 43.25 & l \\
\hline \multirow{6}{*}{ Assimilation SSM only } & SSM & 0.73 & 0.02 & 0.06 & 0.67 \\
\hline & $w_{2}$ & 0.93 & 0.001 & 0.02 & 0.93 \\
\hline & LAI & 0.16 & 0.07 & 0.98 & -0.51 \\
\hline & $\mathrm{CO}_{2}$ & 0.61 & -1.80 & 3.45 & / \\
\hline & $\mathrm{H}$ & 0.79 & -6.64 & 42.10 & / \\
\hline & LE & 0.69 & -1.40 & 41.02 & l \\
\hline \multirow{6}{*}{ Assimilation SSM and LAI } & SSM & 0.73 & 0.02 & 0.06 & 0.67 \\
\hline & $w_{2}$ & 0.94 & 0.001 & 0.02 & 0.94 \\
\hline & LAI & 0.81 & 0.18 & 0.39 & 0.76 \\
\hline & $\mathrm{CO}_{2}$ & 0.65 & -1.61 & 3.23 & I \\
\hline & $\mathrm{H}$ & 0.79 & -6.37 & 42.53 & l \\
\hline & LE & 0.65 & -2.53 & 42.85 & / \\
\hline \multicolumn{6}{|l|}{ Real case } \\
\hline & SSM & $0.640 .70 *$ & $-0.001-0.009 *$ & $0.060 .06^{*}$ & $0.640 .68 *$ \\
\hline Open-loop & $w_{2}$ & $0.770 .77 *$ & $-0.02-0.03 *$ & $0.040 .04 *$ & $0.570 .50 *$ \\
\hline 2001-2007 (left) & LAI & $0.230 .25^{*}$ & $-0.060 .25^{*}$ & $0.890 .80 *$ & $-0.25-0.25^{*}$ \\
\hline \multirow[t]{3}{*}{ 2003-2007 (right) } & $\mathrm{CO}_{2}$ & 0.37 & -1.36 & 3.84 & / \\
\hline & $\mathrm{H}$ & 0.53 & -0.27 & 66.83 & I \\
\hline & LE & 0.52 & -5.48 & 53.05 & I \\
\hline & SSM & $0.660 .71 *$ & $-0.001-0.007 *$ & $0.060 .06^{*}$ & $0.660 .70^{*}$ \\
\hline Assimilation SSM and LAI & $w_{2}$ & $0.810 .82 *$ & $-0.02-0.02 *$ & $0.030 .04 *$ & $0.660 .63 *$ \\
\hline 2001-2007 (left) & LAI & $0.800 .73 *$ & $0.120 .22 *$ & $0.380 .44 *$ & $0.770 .62 *$ \\
\hline \multirow[t]{3}{*}{ 2003-2007 (right) } & $\mathrm{CO}_{2}$ & 0.42 & -1.30 & 3.69 & 1 \\
\hline & $\mathrm{H}$ & 0.54 & -0.23 & 65.99 & / \\
\hline & LE & 0.51 & -5.35 & 53.68 & I \\
\hline \multirow{6}{*}{ Assimilation TB-derived SSM and LAI (*) } & SSM & 0.70 & -0.009 & 0.06 & 0.69 \\
\hline & $w_{2}$ & 0.77 & -0.030 & 0.04 & 0.53 \\
\hline & LAI & 0.75 & 0.19 & 0.40 & 0.68 \\
\hline & $\mathrm{CO}_{2}$ & 0.40 & -1.35 & 3.76 & I \\
\hline & $\mathrm{H}$ & 0.54 & -1.38 & 67.04 & 1 \\
\hline & LE & 0.48 & -3.97 & 53.08 & I \\
\hline
\end{tabular}

Note that the considered period is 2001-2007 for SSM, $w_{2}$ and LAI, and 2005-2007 for the $\mathrm{CO}_{2}$ flux, $\mathrm{H}$ and LE. Bias and RMSE are in units of $\mathrm{m}^{3} \mathrm{~m}^{-3}$ for SSM and $w_{2}, \mathrm{~m}^{2} \mathrm{~m}^{-2}$ for LAI, $\mu \mathrm{mol} \mathrm{m} \mathrm{m}^{-2} \mathrm{~s}^{-1}$ for $\mathrm{CO}_{2}$ flux, and $\mathrm{W} \mathrm{m}^{-2}$ for $\mathrm{H}$ and LE. (*) indicates that for SSM, $w_{2}$ and LAI, the considered period is 2003-2005. 

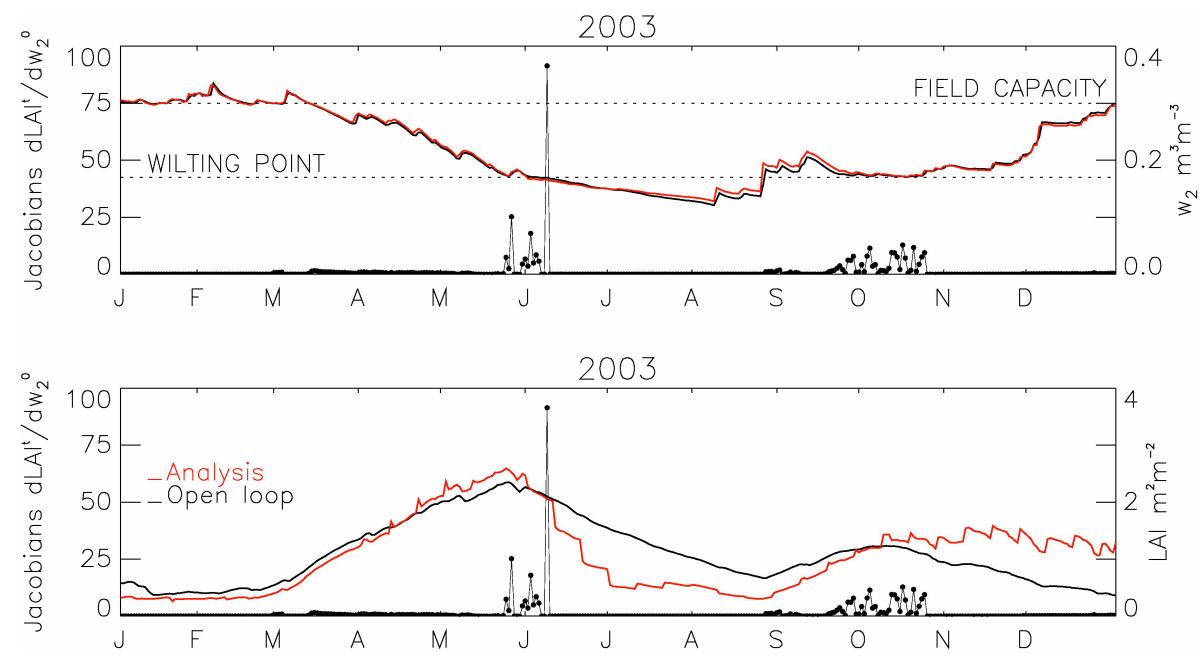

Fig. 5. Analysed (top) root-zone soil moisture and (bottom) LAI, vs. open-loop best case (BC) simulations for the year 2003. Black line is for the $\mathrm{BC}$, red line for the analysis. The $\partial \mathrm{LAI}^{t} / \partial w_{2}^{0}$ Jacobian is represented by the black dots and the fine lines.

RMSE from 0.88 to $0.41 \mathrm{~m}^{2} \mathrm{~m}^{-2}$. Assimilating LAI only has a positive impact on $\mathrm{CO}_{2}$ flux with $r^{2}$ increasing from 0.59 to 0.62 , and mean bias and RMSE dropping from -2.15 to $-1.84 \mu \mathrm{mol} \mathrm{m}^{-2} \mathrm{~s}^{-1}$ and from 3.80 to $3.53 \mu \mathrm{mol} \mathrm{m}^{-2} \mathrm{~s}^{-1}$, respectively. In a previous study, Brut et al. (2009) found that the optimal temperature used in ISBA-A-gs may be too high for $\mathrm{C} 3$ grasslands, resulting in a delay in the simulated leaf onset. A similar difference in temperature response was found by Albergel et al. (2010) for the SMOSREX grassland. Indeed, for the years 2004 to 2007, the BC open-loop simulation presents delayed leaf onsets while the assimilation of LAI measurements tends to increase LAI at springtime. Assimilating SSM only (one observation every 3 days), improves the scores on SSM itself ( $N$ increases from 0.61 to $0.67), w_{2}$ ( $N$ increases from 0.90 to 0.93$)$ but also on LE $\left(r^{2}\right.$ increases from 0.64 to 0.69 , and mean bias and RMSE drop from 2.50 to $1.40 \mathrm{~W} \mathrm{~m}^{-2}$ and from 42.35 to $41.02 \mathrm{~W} \mathrm{~m}^{-2}$, respectively, see Table 3).

Figure 4 presents the BC simulations, open-loop and analysis with the joint assimilation of SSM and LAI. The SSM, $w_{2}$ and LAI variables, either simulated or observed, are shown for the 2001-2007 period. It is easy to appreciate the positive impact of the assimilation on LAI. The $w_{2}$ is markedly improved at different periods, e.g. AugustSeptember 2001 and January-March 2006 among others. The assimilation of both SSM and LAI leads to an overall improvement of all the scores, excepted for $\mathrm{H}$ where the correlation remains at the same level $\left(r^{2}=0.79\right)$. For $w_{2}, r^{2}$ and $N$ increase from 0.91 to 0.94 and from 0.90 to 0.94 , respectively. Concerning $w_{2}$ and the $\mathrm{CO}_{2}$ flux, it is important to note that the best scores are obtained when SSM and LAI are assimilated jointly. For the $\mathrm{CO}_{2}$ flux, $r^{2}$ increases from 0.59 to 0.65 , against $r^{2}=0.62$ with the LAI-only assimilation and 0.61 with the SSM-only assimilation. The same behaviour is observed with $w_{2}$, where $N$ rises from 0.90 to 0.94 with the joint assimilation, as compared to $N=0.90$ and $N=0.93$ for LAI-only and SSM-only assimilations, respectively. However, for LE, the SSM-only assimilation leads to a better result, with $r^{2}=0.69$ against $r^{2}=0.65$ for the joint assimilation. The scores presented in Table 3 show results for multi-annual time series. In the study performed by Sabater et al. (2008), the covariance terms in Eq. (4) are set to 0. It is not the case in this study, it possible to appreciate new Jacobians $\left({ } \mathrm{SSM}^{t} / \partial \mathrm{LAI}^{0}\right.$ and $\left.\partial \mathrm{LAI}^{t} / \partial w_{2}^{0}\right)$. The former is presented in Fig. 5. The Jacobians are governed by the physic of the model which may trigger non-linearities closed to threshold value. When $w_{2}$ is close to the wilting point $\left(0.17 \mathrm{~m}^{3} \mathrm{~m}^{-3}\right)$, there can be a strong sensitivity of LAI to $w_{2}$. In Fig. 5 , the year 2003 is presented. In June, a severe drought induces $w_{2}$ values lower than wilting point and a strong sensitivity of LAI to $w_{2}$. Some variability is also observed in September and October when $w_{2}$ is close to wilting point. The LDAS can exploit this sensitivity in order to fit LAI observations through a modification of $w_{2}$.

\subsection{Best case LDAS with zero precipitation}

In this section, the robustness of the assimilation scheme is tested in a configuration where no information on precipitation is available (i.e. precipitation values set to 0 ). For the SMOSREX site, all the required meteorological data used to run ISBA-A-gs are observed in situ, and constitute the best atmospheric forcing one may use. However, such conditions are rarely reached at large scale. In order to test the resilience of the LDAS to the quality of the atmospheric forcing, the same experiment as above was performed with no precipitation over the entire period. This is a way to verify the ability of the LDAS to restore the overall behaviour of $w_{2}$ 

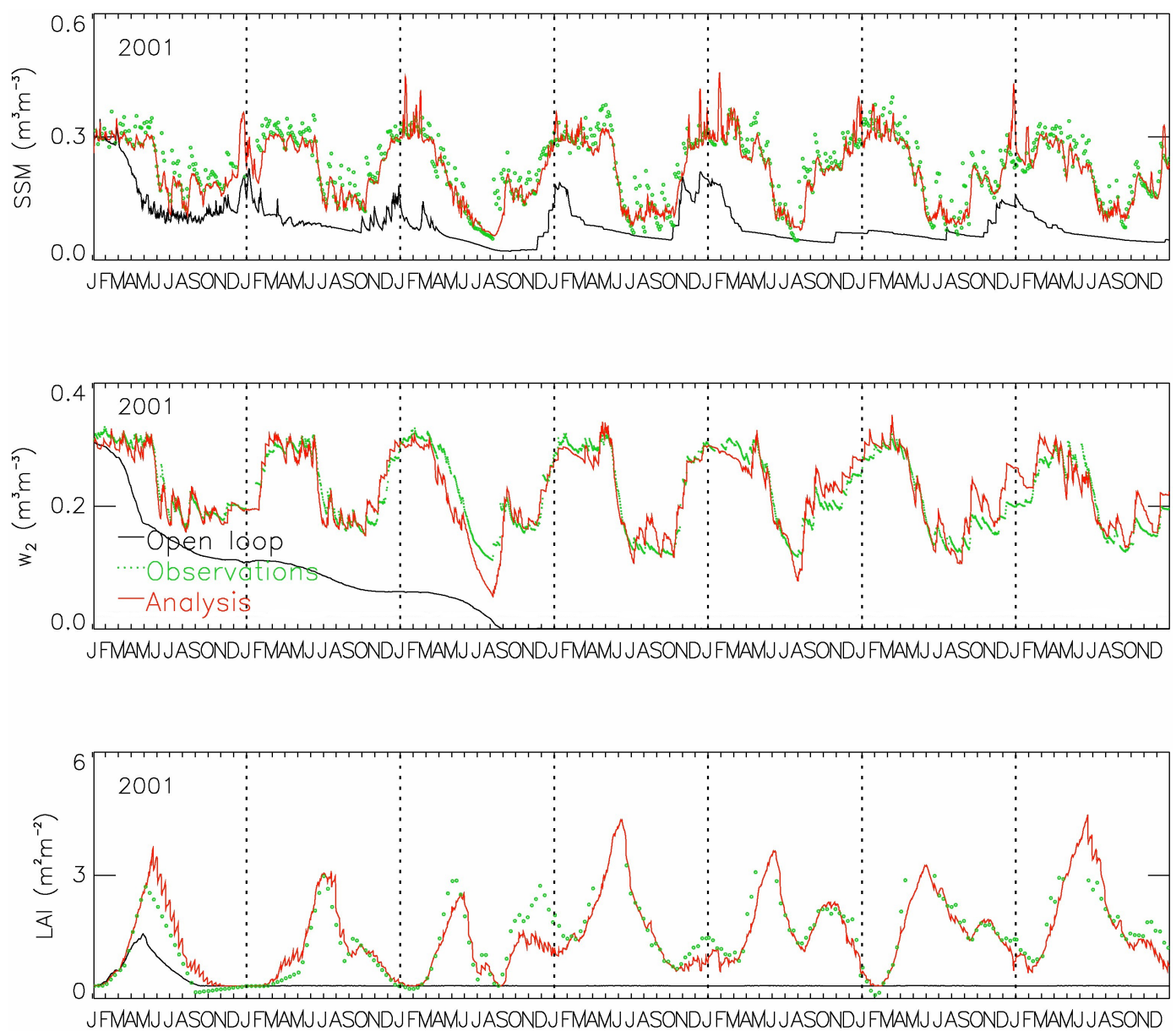

Fig. 6. Same as Fig. 4, except for precipitation set to 0 and SEKF model error multiplied by 3 .

Table 4. Exponential filter and best case, no-precipitation LDAS scores (squared correlation coefficient, mean bias, root mean square error (RMSE) and Nash-Sutcliffe criterion $(N)$ ) on SWI and $w_{2}$, respectively, for the SMOSREX grassland, from 2001 to 2007. For the LDAS, scores are given with and without the assimilation of LAI.

\begin{tabular}{lcccc}
\hline & $r^{2}$ & $\begin{array}{c}\text { bias }\left(\mathrm{m}^{3} \mathrm{~m}^{-3}\right) \text { or }\left(\mathrm{m}^{3} \mathrm{~m}^{-3}\right) \\
\text { and }[-] \text { for filtering method }\end{array}$ & $\begin{array}{c}\text { RMSE }\left(\mathrm{m}^{3} \mathrm{~m}^{-3}\right) \text { or }\left(\mathrm{m}^{3} \mathrm{~m}^{-3}\right) \\
\text { and [-] for filtering method }\end{array}$ & $N$ \\
\hline SSM only & 0.86 & -0.0003 & 0.02 & 0.85 \\
SSM and LAI & 0.84 & -0.0002 & 0.02 & 0.84 \\
Exponential Filter & 0.84 & $-0.001 ;-0.03$ & $0.015 ; 0.11$ & 0.84 \\
\hline
\end{tabular}

Note that the considered period is 2001-2007. Bias and RMSE values for SWI and $w_{2}$, are dimensionless and in units of $\mathrm{m}^{3} \mathrm{~m}^{-3}$, respectively. In units of $\mathrm{m}^{2} \mathrm{~m}^{-2}$ for LAI, $\mu \mathrm{mol} \mathrm{m}{ }^{-2} \mathrm{~s}^{-1}$ for $\mathrm{CO}_{2}$ flux, and $\mathrm{W} \mathrm{m}^{-2}$ for $\mathrm{H}$ and LE.

and SSM (Sabater et al., 2008). Figure 6 presents the result of the assimilation of SSM and LAI, without precipitation in the forcing. In order to account for the degraded performance of the model, a high value of $\mathbf{B}_{w 2}$ is prescribed (see Sect. 2.5). Table 4 underlines the capability of the LDAS to analyse $w_{2}$ in this configuration. The root-zone soil moisture produced by the new analysis matches well with the observations, and the seasonal trend is still represented. Indeed, the use of a low background error (low with respect to the observational error), produces an analysis very close to the open loop and there is no seasonal cycle in $w_{2}$. Without assimilating SSM, values of $w_{2}$ decrease below the wilting point $\left(0.17 \mathrm{~m}^{3} \mathrm{~m}^{-3}\right)$ in a few months. Then, $w_{2}$ decreases slowly down to 0 . Plant growth is possible during the spring of 2001 because the simulation is initialised at field capacity in wintertime. Then, LAI decreases to the prescribed 
minimal value of $0.3 \mathrm{~m}^{2} \mathrm{~m}^{-2}$. The minimum LAI allows non-stomatal evaporation, permitting $w_{2}$ to reach slowly the 0 value. In Sabater et al. (2008) this is not possible as the cuticular conductance is set to $0 \mathrm{~m} \mathrm{~s}^{-1}$. In this paper a value of $3 \times 10^{-4} \mathrm{~m} \mathrm{~s}^{-1}$ is used (BC) and non-stomatal evaporation is accounted for. Figure 6 shows that the advantage of the LDAS over the open-loop BC is considerable, and that the lack of knowledge on the precipitation forcing is compensated, to some extent, by the assimilation. In this configuration, the LDAS scores when assimilating SSM only are: $r^{2}=0.86$, bias and RMSE values of -0.0003 and $0.02 \mathrm{~m}^{3} \mathrm{~m}^{-3}$, respectively, and $N=0.85$ (Table 4). In the joint SSM and LAI assimilation LDAS, very similar scores are obtained. In terms of water budget, the quantity of precipitation removed from the system when considering a no precipitation case should be replaced by the analysis. Over the 2001-2007 period, $4067 \mathrm{~mm}$ of rain are observed and the quantity of water added by the analysis is about $4085 \mathrm{~mm}$. In Fig. 6 (top), non-zero SSM values in the open-loop zeroprecipitation simulation are caused by dew deposition generated by the model. The rather strong impact of dew on the simulated SSM is caused by the very thin top soil layer represented by the model (in this study, a simple force-restore version of the model hydrology is used).

It is interesting to note that, considering no precipitation, the LDAS relies on SSM to retrieve the root zone soil moisture. Results of the LDAS can be used to improve initialisation of soil moisture in NWP models. However for some hydrological applications where soil moisture is the only variable of interest, this configuration can be compared to the simple filtering method presented in Sect. 2.3, based on SSM observations, only. When Eq. (6) is applied to the same SSM data set as previously used by the LDAS (one observation every three days), SWI values are retrieved and can be compared to the $w_{2}$ observations (normalised between [0-1] using the min and max of the time series to be compared to the SWI). The results are presented in Fig. 7 and Table 4. Scores similar to those of the LDAS are found: $r^{2}=0.84$, bias and RMSE values of -0.03 and 0.11 , respectively, and $N=0.84$. When these errors are rescaled using the wilting point and field capacity values used in the model, the following scores are obtained, bias $=-0.001 \mathrm{~m}^{3} \mathrm{~m}^{-3}$ and RMSE $=0.015 \mathrm{~m}^{3} \mathrm{~m}^{-3}$. Even if LDAS and the exponential filter concern different applications, it is showed that this simple technique is helpful to retrieve the root-zone soil moisture variations in areas where surface soil moisture (e.g. estimated from remote sensing) is the only data available.

\subsection{Real case LDAS}

\subsubsection{Assimilating LAI and SSM}

In the previous section, the robustness of the system was tested by greatly decreasing the quality of the atmospheric forcing. In this section, less accurate input parameters and variables are used, in order to assess a configuration closer to operational conditions (real case, or RC experiment). In $\mathrm{RC}$, as previously discussed, the atmospheric forcing from the SAFRAN analysis, soil and vegetation parameters from ECOCLIMAP (Table 1) are used to run ISBA-A-gs over the SMOSREX site. The assimilation of either observed LAI and SSM or SSM only is also performed. As previously noted, the assimilation permits to increase the statistical scores (see Table 3). For SSM and $w_{2}$, bias and RMSE scores between open-loop and LDAS are the same, but the LDAS $r^{2}$ and $N$ are higher. For SSM, the $r^{2}$ score increases from 0.64 to 0.66 , and $N$ from 0.64 to 0.66 . For $w_{2}, r^{2}$ increases from 0.77 to 0.81 , and $N$ from 0.57 to 0.66 . For LAI, it is easy to appreciate the added value of the assimilation: $r^{2}$, bias, RMSE and $N$ scores change from 0.23 to $0.80,-0.06$ to $0.12 \mathrm{~m}^{2} \mathrm{~m}^{-2}, 0.89$ to $0.38 \mathrm{~m}^{2} \mathrm{~m}^{-2}$ and -0.25 to 0.77 , respectively (Table 3 ). The main differences between the open-loop, BC and RC consist of the level reached by $w_{2}$ during the summer period (see Fig. 2). This is due to differences in clay and sand fractions, as well as in wilting point and field capacity values.

\subsubsection{Assimilating soil moisture from TB}

In the previous sections, direct in situ observations of SSM were used. A further step is the assimilation of SSM data derived from the inversion of the L-band TB measured by the LEWIS radiometer, resulting in a new five-year SSM data set. As LEWIS data are available from 2003 to 2007, only this period is now considered (without the first two years previously included). The statistical scores for the entire 20032007 period are presented in Table 3, for the open-loop RC and for the joint assimilation of the TB-derived SSM and LAI. Table 5 summarizes the yearly LDAS scores for SSM, $w_{2}$ and LAI. In 2005 and 2007, the assimilation does not increase the quality of the results (for $w_{2}, r^{2}$ drops from 0.78 to 0.75 and from 0.72 to 0.62 , respectively). It can be noted in Fig. 1 that while the RMSE between SSM and the TB-derived SSM is about $0.04 \mathrm{~m}^{3} \mathrm{~m}^{-3}$ in 2003, 2004, and 2006, it presents higher values in 2005 and 2007 (0.06 and $0.07 \mathrm{~m}^{3} \mathrm{~m}^{-3}$, respectively). This can explain the lower LDAS scores for those two years. For those specific years, greater observational errors should have increased statistical scores.

\section{Discussion}

The LDAS is first tested over the SMOSREX experimental site in optimal modelling conditions (observed atmospheric forcing and biophysical parameters) over a seven year period (2001-2007). This permits to demonstrate the potential of assimilating SSM and LAI, either separately or jointly. The joint assimilation of LAI and SSM tends to give the best scores for all the variables, including carbon fluxes, $\mathrm{H}$ and 


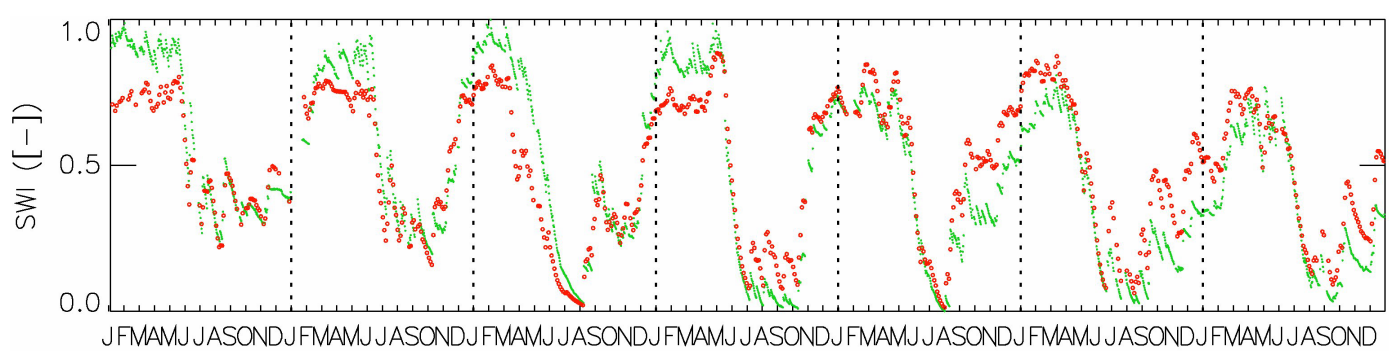

Fig. 7. SWI retrieval using the recursive formulation of the exponential filter over the 2001-2007 period. The observed SWI is in green and the retrieved is in red using the same data set as for the data assimilation.

Table 5. Yearly model open-loop and LDAS scores (squared correlation coefficient, mean bias, root mean square error (RMSE) and NashSutcliffe criterion $N$ ) on state variables (SSM, $w_{2}$ and LAI) for the SMOSREX grassland, in the "real case" configuration with L-band radiometry derived SSM estimates.

\begin{tabular}{|c|c|c|c|c|c|c|c|c|c|c|c|}
\hline & & \multicolumn{2}{|c|}{2003} & \multicolumn{2}{|c|}{2004} & \multicolumn{2}{|c|}{2005} & \multicolumn{2}{|c|}{2006} & \multicolumn{2}{|c|}{2007} \\
\hline & & open-loop & analysis & open-loop & analysis & open-loop & analysis & open-loop & analysis & open-loop & analysis \\
\hline \multirow{4}{*}{$\begin{array}{c}\text { SSM } \\
\left(\mathrm{m}^{3} \mathrm{~m}^{-3}\right)\end{array}$} & $r^{2}$ & 0.69 & 0.69 & 0.74 & 0.73 & 0.79 & 0.79 & 0.69 & 0.71 & 0.60 & 0.57 \\
\hline & $\operatorname{bias}\left(\mathrm{m}^{3} \mathrm{~m}^{-3}\right)$ & -0.03 & -0.03 & -0.001 & 0.001 & 0.001 & 0.003 & -0.002 & -0.0008 & -0.011 & -0.016 \\
\hline & $\operatorname{RMSE}\left(\mathrm{m}^{3} \mathrm{~m}^{-3}\right)$ & 0.06 & 0.06 & 0.06 & 0.06 & 0.04 & 0.04 & 0.06 & 0.06 & 0.06 & 0.06 \\
\hline & $N$ & 0.61 & 0.61 & 0.72 & 0.72 & 0.78 & 0.78 & 0.68 & 0.70 & 0.58 & 0.53 \\
\hline \multirow{2}{*}{$\left(\mathrm{m}^{3} \mathrm{~m}^{-3}\right)$} & $r^{2}$ & 0.77 & 0.82 & 0.90 & 0.90 & 0.78 & 0.75 & 0.70 & 0.79 & 0.72 & 0.62 \\
\hline & $N$ & 0.65 & 0.71 & 0.67 & 0.75 & 0.51 & 0.56 & 0.22 & 0.31 & 0.25 & -0.02 \\
\hline \multirow{4}{*}{$\begin{array}{c}\text { LAI } \\
\left(\mathrm{m}^{2} \mathrm{~m}^{-2}\right)\end{array}$} & $r^{2}$ & 0.01 & 0.72 & 0.09 & 0.80 & 0.43 & 0.76 & 0.79 & 0.89 & 0.51 & 0.76 \\
\hline & $\operatorname{bias}\left(\mathrm{m}^{2} \mathrm{~m}^{-2}\right)$ & 0.26 & 0.32 & 0.35 & 0.19 & 0.28 & 0.17 & 0.28 & 0.09 & 0.08 & 0.13 \\
\hline & $\operatorname{RMSE}\left(\mathrm{m}^{2} \mathrm{~m}^{-2}\right)$ & 1.05 & 0.58 & 0.81 & 0.33 & 0.59 & 0.32 & 0.48 & 0.27 & 0.88 & 0.39 \\
\hline & $N$ & -0.41 & 0.55 & -0.81 & 0.68 & -0.15 & 0.65 & 0.61 & 0.87 & -1.17 & 0.57 \\
\hline
\end{tabular}

LE (Table 3). The same experiment using a lower-quality atmospheric forcing and generic biophysical parameters, also displays a good performance, but to a lesser degree. It is also shown that large errors on precipitation can be counterbalanced, to some extent, by the assimilation system. The motivation for focusing on precipitation is that this meteorological variable is generally more difficult to monitor in data-poor areas. Table 4 shows, that a simple exponential filter deriving SWI information from SSM times series is also of interest for deriving $w_{2}$ variability. The simple exponential filter produces a proxy of the root-zone soil moisture, but has not the LDAS capacity of monitoring the surface fluxes and the vegetation biomass. The two techniques may be complementary as both SSM and SWI will be soon operationally available. The assimilation of SWI by the LDAS, instead of SSM, is being investigated. In applications focussing on SWI only, this very simple method might be a good alternative to LDAS, especially in areas where the availability of in situ observations of atmospheric variables (especially precipitation) or on soil characteristics is poor. The rationale for using a SWI instead of volumetric root zone soil moisture is that over large areas the variability of soil properties may be very high and may not be represented accurately. In this context only the relative dynamical range of the soil water content can be represented (Rüdiger et al., 2009).

The assimilation of a SSM data set derived from the inversion of observed L-band brightness temperatures shows that the result of the assimilation depends on the accuracy of the SSM retrievals, which is found to vary from year to year. The assimilation of TB-derived SSM (jointly with LAI) leads to lower scores over the 2003-2007 period, especially for 2007 (Table 5). This can be explained by the lower quality of the soil moisture retrievals from the LEWIS TB at SMOSREX, a grassland with a thick litter which tends to mask the soil microwave emission. Over the SMOSREX grassland, ISBAA-gs forced with either an observed atmospheric forcing or with the SAFRAN analysis already presents good results and it is difficult for the assimilation to significantly improve the model performance. However the solidity and ability of the LDAS to monitor water and carbon fluxes over the SMOSREX grassland is demonstrated in this study. It is likely that over areas where all the data necessary to run a 
LSM model such as ISBA-A-gs are available and of good quality (e.g. over France with the SAFRAN analysis), the assimilation of SSM would only slightly improve the simulations. On the other hand, the joint assimilation of LAI and SSM is shown to improve significantly the LAI and carbon flux simulations which is of interest for land carbon monitoring.

Also, while previous studies have shown that the assimilation of LAI with long assimilation windows (e.g. 10 days) is possible, it is shown that a 1-day assimilation window can be used by a LDAS designed to comply with NWP requirements and other operational models (e.g. SIM, Habets et al., 2008). For surface soil moisture, using a single observation every three days is justified by the sampling time of satellites. This issue was discussed by Calvet and Noilhan (2000). They found that a 3-day sampling time for SSM is small enough to retrieve $w_{2}$ and that below 4 days, the sampling time has little influence on the quality of the retrievals. A similar result was obtained by Walker and Houser (2004) with an EKF. It was checked (not shown) that a similar result is obtained with the LDAS used in this study. Assimilating SSM more frequently increases the SSM scores but has little impact on $w_{2}$. This is probably due to the use of an SEKF where the background error covariance matrix is assumed to be constant: at the start of each assimilation window, the "soil memory" of the model is not accounted for.

Setting errors is not easy. An appropriate selection of the error (co)variances is crucial to achieve a good performance of the Kalman filter. In this study, they were set using information from previous studies. The probability density function of the innovations is Gaussian, with a variance of about $0.0066\left(\mathrm{~m}^{3} \mathrm{~m}^{-3}\right)^{2}$ and a mean of $0.04 \mathrm{~m}^{3} \mathrm{~m}^{-3}$. Moreover, the value of $0.0036\left(\mathrm{~m}^{3} \mathrm{~m}^{-3}\right)^{2}$ used for $\mathbf{R}_{\mathrm{SSM}}$ (observational errors) is similar to the estimated errors, $0.06 \mathrm{~m}^{3} \mathrm{~m}^{-3}$, found for ASCAT remotely sensed estimates (Albergel et al., 2009). It is unlikely that the optimization of $\mathbf{B}_{w 2}$ performed for the SMOSREX site be valid for other sites or regions. Mahfouf et al. (2009) and Draper et al. (2009) assume that $\mathbf{B}_{w 2}^{0.5}$ is proportional to the soil moisture range (i.e. the difference between $w_{\mathrm{fc}}$ and $\left.w_{\text {wilt }}\right)$. For LAI, Sabater et al. (2008) used a constant value of $1 \mathrm{~m}^{2} \mathrm{~m}^{-2}$ (for both model and observation errors) and Jarlan et al. (2008) used a constant value of $1 \mathrm{~m}^{2} \mathrm{~m}^{-2}$ for observation errors, and a relative model error of $20 \%$. Setting a constant value of $1 \mathrm{~m}^{2} \mathrm{~m}^{-2}$ for the simulated LAI introduces discrepancies in periods where LAI is low (e.g. from the end of summer to spring). The study performed by Rüdiger et al. (2010) on the evaluation of the Jacobians for LAI data assimilation with an EKF supports the finding of Jarlan et al. (2008) as it underlines the need for a variable error definition.

\section{Conclusion}

A Simplified Extended Kalman Filter was used within the SURFEX modelling platform of Météo-France, in order to assess the impact on the simulations of the ISBA-A-gs LSM of assimilating SSM and/or LAI observations. This study demonstrates:

1. The ability of the LDAS to monitor the carbon and water fluxes, and the advantage of performing a joint assimilation of both SSM and LAI observations. Some variables like $w_{2}$, LAI and the surface fluxes present better results when both SSM and LAI are assimilated.

2. The robustness of the LDAS when the quality of the atmospheric forcing is degraded. A test with zero precipitation and the use of an operational atmospheric analysis (SAFRAN) show that the joint assimilation of LAI and SSM permits to overcome errors from the forcing.

The usefulness of simpler methods like the exponential filtering, to retrieve a SWI has also been demonstrated. Finally, the added value of a LDAS depends, to a large extent, on the quality of the model. In situations where the atmospheric variables and the biophysical parameters of the model are well characterised, the data assimilation has a limited impact on the simulations. In data poor areas, the assimilation of satellite-derived surface variables, is more likely to improve the behaviour of the land surface model. Draper et al. (2009) have shown the potential of the assimilation of satellite-derived SSM values in NWP applications, at a continental scale. In this study, the same LDAS is extended to the assimilation of LAI observations, the simulation of the surface carbon fluxes, and verified with in situ flux and soil profile observations at the local scale, without coupling with the atmosphere. This shows that the assimilation systems used in meteorology are flexible enough to assimilate new satellite observations, and can be adapted for environment monitoring applications, not coupled with atmospheric models. A step further is an improvement of the SEKF into an EKF which requires a more in depth analysis for the specification of model errors.

Acknowledgements. The work of C. Albergel was supported by Centre National d'Etudes Spatiales (CNES) and Météo-France. The SMOSREX project was co-funded by the "Programme National de Télédétection Spatiale" and by the "Programme Terre Océan Surface Continentales et Atmosphère" (CNES), and by participants to the experiment: CESBIO (CNES, CNRS, IRD, UPS), CNRM/GAME (Météo-France, CNRS), INRA, and ONERA, all in the framework of the SMOS science preparatory program. Jeffrey Walker's visit to CNRM was supported by the STAE (Sciences et Technologies pour l'Aéronautique et l'Espace) foundation, in the framework of the CYMENT project. This work is a contribution to the geoland 2 project, co-funded by the European Commission within the GMES initiative in FP7.

Edited by: W. Wagner 


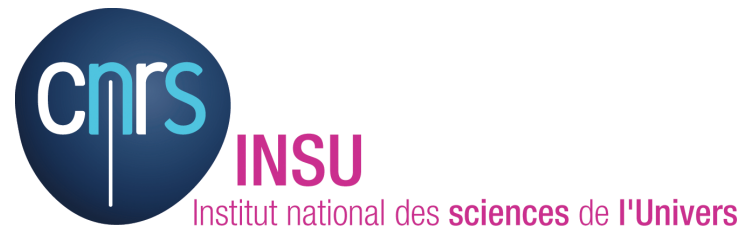

The publication of this article is financed by CNRS-INSU.

\section{References}

Albergel, C., Rüdiger, C., Pellarin, T., Calvet, J.-C., Fritz, N., Froissard, F., Suquia, D., Petitpa, A., Piguet, B., and Martin, E.: From near-surface to root-zone soil moisture using an exponential filter: an assessment of the method based on in-situ observations and model simulations, Hydrol. Earth Syst. Sci., 12, 1323-1337, doi:10.5194/hess-12-1323-2008, 2008.

Albergel, C., Rüdiger, C., Carrer, D., Calvet, J.-C., Fritz, N., Naeimi, V., Bartalis, Z., and Hasenauer, S.: An evaluation of ASCAT surface soil moisture products with in-situ observations in Southwestern France, Hydrol. Earth Syst. Sci., 13, 115-124, doi:10.5194/hess-13-115-2009, 2009.

Albergel, C., Calvet, J.-C., Gibelin, A.-L., Lafont, S., Roujean, J.L., Berne, C., Traullé, O., and Fritz, N.: Observed and modelled ecosystem respiration and gross primary production of a grassland in southwestern France, Biogeosciences, 7, 1657-1668, doi:10.5194/bg-7-1657-2010, 2010.

Aubinet, M., Grelle, A., Ibrom, A., Rannik, Ü., Moncrieff, J., Foken, T., et al.: Estimates of the Annual Net Carbon and Water Exchange of Forests: The EUROFLUX Methodology, Adv. Ecol. Res., 30, 113-175, IBSN 0-12-013930-8, 2000.

Balsamo, G., Bouyssel, F., and Noilhan, J.: A simplified bi dimensional variationnal analysis of soil moisture for screen-level observations in a mesoscale numerical weather prediction model, Q. J. Roy. Meteorol. Soc., 130, 895-915, 2004.

Brut, A., Rüdiger, C., Lafont, S., Roujean, J.-L., Calvet, J.-C., Jarlan, L., Gibelin, A.-L., Albergel, C., Le Moigne, P., Soussana, J.-F., Klumpp, K., Guyon, D., Wigneron, J.-P., and Ceschia, E.: Modelling LAI at a regional scale with ISBA-A-gs: comparison with satellite-derived LAI over southwestern France, Biogeosciences, 6, 1389-1404, doi:10.5194/bg-6-1389-2009, 2009.

Calvet, J.-C., Noilhan, J., Roujean, J.-L., Bessemoulin, P., Cabelguenne, M., Olioso, A., and Wigneron, J.-P.: An interactive vegetation SVAT model tested against data from six contrasting sites, Agr. Forest Meteorol., 92, 73-95, 1998.

Calvet, J.-C., Bessemoulin, P., Noilhan, J., Berne, C., Braud, I., Courault, D., Fritz, N., Gonzalez-Sosa, E., Goutorbe, J.-P., Haverkamp, R., Jaubert, G., Kergoat, L., Lachaud, G., Laurent, J.-P., Mordelet, P., Olioso, A., Péris, P., Roujean, J.-L., Thony, J.-L., Tosca, C., Vauclin, M., and Vignes, D.: MUREX: a land-surface field experiment to study the annual cycle of the energy and water budgets, Ann. Geophys., 17, 838-854, doi:10.1007/s00585-999-0838-2, 1999.

Calvet, J.-C. and Noilhan, J.: From near-surface to root-zone soil moisture using year-round data, J. Hydrometeor., 1, 393-411, 2000.

Calvet, J.-C.: Investigating soil and atmospheric plant water stress using physiological and micrometeorological data, Agr. Forest Meteorol., 103, 229-247, 2000.
Calvet, J.-C., Rivalland, V., Picon-Cochard, C., and Guelh, J.M.: Modelling forest transpiration and $\mathrm{CO}_{2}$ fluxes-response to soil moisture stress, Agr. Forest Meteorol., 124(3-4), 143-156, doi:10.1016/j.agrformet.2004.01.007, 2004.

Calvet, J.-C., Gibelin, A.-L., Roujean, J.-L., Martin, E., Le Moigne, P., Douville, H., and Noilhan, J.: Past and future scenarios of the effect of carbon dioxide on plant growth and transpiration for three vegetation types of southwestern France, Atmos. Chem. Phys., 8, 397-406, doi:10.5194/acp-8-397-2008, 2008.

Crow, W. T. and Reichle, R. H.: Comparison of adaptive filtering techniques for land surface data assimilation, Water Resour. Res., 44, W08423, doi:10.1029/2008WR006883, 2008.

De Rosnay, P., Calvet, J.-C., Kerr, Y., Wigneron, J.-P., Lemaître, F., et al.: SMOSREX: A long term field campaign experiment for soil moisture and land surface processes remote sensing, Remote Sens. Environ., 102, 377-389, 2006.

Draper, C. S., Mahfouf, J.-F., and Walker, W.: An EKF assimilation of AMSR-E soil moisture into the ISBA land surface scheme, $\mathrm{J}$ Geophys. Res., 114, D20104, doi:10.1029/2008JD011650, 2009.

Drusch, M., Wood, E. F., and Gao, H.: Observations operators for the direct assimilation of TRMM microwave imager retrieved soil moisture, Geophys. Res. Lett., 32, L15403, doi:10.1029/2005GL023623, 2005.

Durand, Y., Brun, E., Merindol, L., Guyomarc'h, G., Lesaffre, B., and Martin, E.: A meteorological estimation of relevant parameters for snow models, Ann. Glaciol., 18, 65-71, 1993.

Entekhabi, D., Nakamura, H., and Njoku, E. G.: Solving the Inverse problem for soil moisture and temperature profiles by sequential assimilation of multifrequency remotely sensed observations, IEEE T. Geosci. Remote, 32(2), 438-448, 1994.

Entekhabi, D., Njoku, E. G., Houser, P., et al.: The hydrosphere state (Hydros) satellite mission: An earth system pathfinder for global mapping of soil moisture and land freeze/thaw, IEEE T. Geosci. Remote, 42(10), 2184-2195, doi:10.1109/TGRS.2004.834631, 2004.

Gibelin, A.-L., Calvet, J.-C., Roujean, J.-L., Jarlan, L., and Los, S. O.: Ability of the land surface model ISBA-A-gs to simulate leaf area index at global scale: Comparison with satellites products, J. Geophys. Res., 111, D18102, doi:10.1029/2005JD006691, 2006.

Habets, F., Boone, A., Champeaux, J.-L., Etchevers, P., Franchisteguy, L., et al.: The SAFRAN-ISBA-MODCOU hydrometeorological model applied over France, J. Geophys. Res., 113, D06113, doi:10.1029/2007JD008548, 2008.

Houser, P. R., Shuttleworth, W. J., Famiglietti, J. S., Gupta, H. V., Syed, K. H., et al.: Integration of Soil Moisture Remote Sensing and Hydrologic Modelling Using Data Assimilation, Water Resour. Res., 34(12), 3405-3420, 1998.

Jarlan, L., Balsamo, G., Lafont, S., Beljaars, A., Calvet, J.-C., and Mougin, E.: Analysis of leaf area index in the ECMWF land surface model and impact on latent heat and carbon fluxes: Application to West Africa, J. Geophys. Res., 113, D24117, doi:10.1029/2007JD009370, 2008.

Kerr, Y., Waldteufel, P., Wigneron, J.-P., Martinuzzi, J.-M., Font, J., and Berger, M.: Soil Moisture retrieval from space: the Soil Moisture and Ocean Salinity (SMOS) mission, IEEE T. Geosci. Remote, 39, 1729-1736, 2001.

Kerr, Y.: Soil moisture from space: Where are we?, Hydrogeol. J., 15(1), 117-120, 2007.

Lemaître, F., Poussière, J.-C., Kerr, Y., Dejus, M., Durbe, R., de 
Rosnay, P., et al.: Design and test of the groud based L-band radiometer for Estimating Water In Soils (LEWIS), IEEE T. Geosci. Remote, 42(8), 1666-1676, 2004.

Le Moigne, P., Boone, A., Calvet, J.-C., Decharme, B., Faroux, S., et al. : SURFEX scientific documentation, Groupe de météorologie à moyenne échelle, note de centre, 87, 211 pp., 2009.

Mahfouf, J.-F., Bergaoui, K., Draper, C., Bouyssel, F., Taillefer, F., and Taseva, L.: A comparison of two off-line soil analysis schemes for assimilation of screen level observations, J. Geophys. Res., 114, D08105, doi:10.1029/2008JD011077, 2009.

Martin, E., Le Moigne, P., Masson, V., Boone, A., Bogatchev, A., et al.: Le code de surface externalisée SurfEx de Météo-France. Atelier de modélisation de l'atmosphère, Toulouse, 16-17 January 2007.

Masson, V., Champeaux, J.-L., Chauvin, F., Meriguet, C., and Lacaze, R.: A global database of land surface parameters at $1 \mathrm{~km}$ resolution in meteorological and climate models, J. Climate, 9, 1261-1282, 2003.

Moncrieff, J., Valentini, R., Greco, S., Seufert, G., and Ciccioli, P.: Trace gas exchange over terrestrial ecosystems: method and perspectives in micrometeorology, J. Exp. Bot., 48, 1133-1142, 1997.

Nash, J. and Sutcliffe, J.: River flow forecasting through conceptual models, part Ii - a discussion and principles, J. Hydrol., 10, 282290, 1970.

Njoku, E.-G., Jackson, T. J., Lakshmi, V., Chan, T. K., and Nghiem, S. V.: Soil moisture retrieval from AMSR-E, IEEE T. Geosci. Remote, 41(2), 21-123, 2003.

Noilhan, J. and Planton, S.: A simple parameterisation of Land Surface Processes for meteo-rological model, Mon. Weather Rev., 117, 356-549, 1989.

Noilhan, J. and Mahfouf, J.-F.: The ISBA land surface parameterisation scheme, Global Planet. Change, 13, 145-149, 1996.

Owe, M., de Jeu, R., and Walker, J.: A methodology for surface soil moisture and vegetation depth retrieval using the microwave polarization difference index, IEEE T. Geosci. Remote, 39, 16431654, 2001.

Owe, M., de Jeu, R., and Holmes, T. : Multisensor historical climatology of satellite-derived global land surface soil moisture, J. Geophys. Res., 110, F01002, doi:10.1029/2007JF000769, 2008.

Quintana Seguí, P., Lemoigne, P., Durand, Y., Martin, E., Habets, F., et al.: Analysis of near surface atmospheric variables: Validation of the SAFRAN analysis over France, J. Appl. Meteorol. Clim., 47, 92-107, 2008.

Ragab, R.: Towards a continuous operational system to estimate the root-zone soil moisture from intermittent remotely sensed surface soil moisture, J. Hydrol., 173(1-4), 1-25, 1995.

Reichle, R. H., McLaughlin, D. B., and Entekhabi, D.: Variational data assimilation of microwave radiobrightness observations for land surface hydrology applications, IEEE T. Geosci. Remote, 39, 1708-1718, 2001.

Reichle, R. H. and Koster, D.: Bias reduction in short records of satellite soil moisture, Geophys. Res. Lett., 31, L19501, doi:10.1029/2004GL020938, 2004.
Reichle, H. R., Crow, W. T., and Keppenne, C. L.: An adaptive ensemble Kalman filter for soil moisture data assimilation, Water Resour. Res., 44, W03423, doi:10.1029/2007WR006357, 2008.

Roujean, J.-L. and Lacaze, R.: Global mapping of vegetation parameter from POLDER multi-angular measurements for studies of surface-atmosphere interactions: A pragmatic method and its validation, J. Geophys. Res., 107(D12), 4150, doi:10.1029/2001JD000751, 2002.

Rüdiger, C., Calvet, J.-C., Gruhier, C., Holmes, T., De Jeu, R., and Wagner, W.: An intercomparison of ERS-Scat and AMSR-E soil moisture observations with model simulations over France, J. Hydrometeorol., 10, 431-447, doi:10.1175/2008JHM997.1, 2009.

Rüdiger, C., Albergel, C., Mahfouf, J.-F., Calvet, J.-C., and Walker, J. P. : Evaluation of Jacobians for Leaf Area Index Data Assimilation with an Extended Kalman Filter, J. Geophys. Res., 115, D09111, doi:10.1029/2009JD012912, 2010.

Sabater, J. M., Jarlan, L., Calvet, J.-C., Bouyssel, F., and De Rosnay, P.: From near surface to root zone soil moisture using different assimilation techniques, J. Hydrometeorol., 8(2), 194-206, 2007.

Sabater, J. M., Rüdiger, C., Calvet, J.-C., Fritz, N., Jarlan, L., and Kerr, Y.: Joint assimilation of surface soil moisture and LAI observations into land surface model, Agr. Forest Meteorol., 148, 1362-1373, doi:10.1016/j.agrformet.2008.04.003, 2008.

Saleh, K., Wigneron, J.-P., Waldteufel, P., de Rosnay, P., Schwank, M., Calvet, J.-C., and Kerr, Y. H.: Estimates of surface soil moisture under grass covers using L-band radiometry, Remote Sens. Environ., 109, 42-53, doi:10.1016/j.rse.2006.12.002, 2007.

Schmugge, T. J.: Remote Sensing of Soil Moisture: Recent Advances, IEEE T. Geosci. Remote, GE21, 145-146, 1983.

Shukla, J. and Mintz, Y.: Influence of Land-Surface Evapotranspiration on the Earth's Climate, Science, 215(4539), 1498-1501, doi:10.1126/science.215.4539.1498, 1982.

Wagner, W., Lemoine, G., and Rott, H.: A method for estimating soil moisture from ERS scat-terometer and soil data, Remote Sens. Environ., 70, 191-207, 1999.

Wagner, W., Blöschl, G., Pampaloni, P., Calvet, J.-C., Bizzarri, B., Wigneron, J.-P., and Kerr, Y.: Operational readiness of microwave remote sensing of soil moisture for hydrologic applications, Nord. Hydrol., 38(1), 1-20, doi:10.2166/nh2007.029, 2007.

Walker, J. P., Willgoose, G. R., and Kalma, J. D.: One-dimensional soil moisture profile retrieval by assimilation of near-surface measurements: A simplified soil moisture model and field application, J. Hydrometeorol., 2, 356-373, 2001.

Walker, J. P. and Houser, P. R.: Requirements of a global near-surface soil moisture satellite mission: accuracy, repeat time, and spatial resolution, Adv. Water Resour., 27, 785-801, doi:10.1016/j.advwatres.2004.05.006, 2004.

Wigneron, J.-P., Kerr, Y., Waldteufel, P., Saleh, K., Escorihuela, M.J., Richaume, P., Ferrazzoli, P., de Rosnay, P., Gurney, R., Calvet, J.-C., Grant, J.P. , Guglielmetti, M., Hornbuckle, B., Mätzler, C., Pellarin, T., and Schwank, M.: L-band Microwave Emission of the Biosphere (L-MEB) Model: Description and calibration against experimental data sets over crop fields, Remote Sens. Environ., 107, 639-655, 2007. 